\title{
A carteira de Sarita: as (im)possibilidades de alunas travestis e transexuais na educação escolar
}

\section{Sarita's desk: the (im)possibilities of transvestite and transsexual students in school education}

\author{
Fábio Carvalho ${ }^{1}$ \\ Émina Santos ${ }^{2}$ \\ Alberto Damasceno ${ }^{3}$
}

\section{Resumo}

Este artigo discute aspectos do processo de escolarização formal de alunas travestis e transexuais, tendo por objetivo, debater algumas das dificuldades enfrentadas no cotidiano escolar. Entre as dificuldades enfrentadas serão discutidas: uso o nome social, reivindicação pelo uso do banheiro feminino, e por fim, a interação das estudantes trans com os demais alunos e alunas da escola. Pressupondo, deste modo, que o processo formal de escolarização destes sujeitos revela-se difícil e penoso. Foi utilizada como metodologia, para construção deste trabalho, análise bibliográfica e entrevista com uma aluna travesti da educação básica do estado do Pará.

Palavras-chave: Identidade Trans, Transfobia, Evasão Escolar.

\begin{abstract}
This article discusses aspects of transvestite and transgender's formal schooling process, by having objective, debate out some of the difficulties in everyday school life. Among the difficulties faced: the use of social name, by the revindication for using the ladies' toilet, and finally, the interaction of transgender girls with other school students. Presupposing, therefore, that the formal schooling process of these subjects proves to be difficult and painful. We used, as a methodology for designing this study, the literature review and an interview with a transsexual student of basic education in the state of Pará.
\end{abstract}

keywords: Trans Identity, Transphobia, School dropout.

\footnotetext{
1 Mestre em Educação (Universidade Federal do Paraná). Profissional em Atendimento Especializado (Instituto Federal de Santa Catarina). Integrante do GILDA - Grupo Interdisciplinar em Linguagem, Diferença e Subjetivação (UFPR/CNPq). E-mail: fabio.ufpa2009@hotmail.com

2 Doutora em Ciências Sócio Ambientais (Universidade Federal do Pará). Professora Titular da Universidade Federal do Pará (UFPA). Coordenadora do Grupo de estudos em Educação em Direitos Humanos (GEEDH). E-mail: emina@ufpa.br

3 Doutor em Educação (Pontifícia Universidade Católica - São Paulo). Professor Titular da UFPA. Docente no Programa de Pós-graduação em Currículo e Gestão da Escola Básica (PPEB-UFPA). Coordenador do Laboratório de Pesquisas em Memória e História da Educação (LAPEM). E-mail: albertod@ufpa.br
} 


\section{Introdução}

Dentre os debates que emergem na sociedade brasileira atualmente, muito em função da mídia impressa e televisiva, a diversidade sexual e de identidade de gênero têm sido objeto de uma polêmica que atingiu diferentes setores da sociedade, se constituindo em um direito humano cuja garantia formal ainda se revela frágil no Brasil.

Após breve estudo do Grupo de Estudos em Educação em Direitos Humanos (GEEDH/UFPA) sobre a construção da identidade trans, a partir de um recorte intencional, objetivou-se discutir um aspecto do processo de escolarização formal de pessoas travestis e transexuais e debater algumas das dificuldades enfrentadas no cotidiano escolar, por se tratar de um segmento de pessoas que tem um elevado número de sua população fora da escola, sem o nível básico de escolaridade.

A construção deste trabalho consiste numa pesquisa bibliográfica. Em seu aporte teórico, destaca-se o referencial da ativista trans, escritora, professora, doutora em Psicologia Jaqueline Gomes de Jesus, de onde se extraiu alguns conceitos básicos relativos à construção do conceito de gênero. Também, alguns trabalhos de Dayana Brunetto, que em sua dissertação de mestrado fez um estudo sobre a experiência de travestis e transexuais na instituição escolar, além de conceitos importantes dos teóricos Michael Foucault e Judith Butler.

Foi realizada também uma entrevista com uma ex-aluna travesti da rede pública de ensino do Estado do Pará. Sarita Chay, nossa entrevistada, nascida no município de Monte Alegre. Hoje com 33 anos, trabalha como empregada doméstica, e teve que enfrentar desde muito cedo em seu cotidiano escolar, práticas discriminatórias e preconceituosas por se identificar como travesti, que a levaram a desistir de continuar seu processo de escolarização formal.

Ainda, como ferramenta teórico-metodológica, recorremos às teorizações foucaultianas, especialmente sua noção da análise discursiva, com o objetivo de fazer a investigação do objeto de pesquisa, a partir do material empírico produzido, no âmbito da 


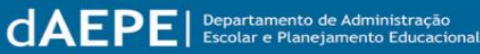

pesquisa bibliográfica e da entrevista. Diante deste suporte metodológico, elegemos três dificuldades enfrentadas por estes sujeitos na instituição escolar, dificuldades relatadas por nossa entrevistada e observadas também na pesquisa bibliográfica com grande frequência no que diz respeito a estas experiências escolares, que passamos a dispor.

\section{Diversidade sexual e de identidade de gênero como Direito Humano}

Ao debater-se a temática da diversidade da identidade de gênero através da ótica do direito humano, podemos partir do conceito mais amplo que define direito humano como sendo todos os direitos civis, políticos, religiosos, entre outros direitos normatizados ou não, pelo simples fato de ser humano. Esses direitos buscam ser garantidos através de princípios que segundo Leite (2011), são autênticas normas jurídicas, sendo certo que alguns deles ocupam o degrau mais alto da pirâmide normativa dos diversos ordenamentos jurídicos estatais, que em sua grande maioria, estão estabelecidos em documentos normativos.

Neste sentido, podemos ressaltar o princípio da dignidade humana, que está estabelecido no art. $1^{\circ}$ da Declaração Universal dos Direitos Humanos o qual declara que "Todos os seres humanos nascem livres em dignidade e em diretos. Dotados de razão e de consciência, devem agir uns para com os outros em espírito de fraternidade”. Cabe aqui observar que, quando não se garante o princípio da dignidade da pessoa humana, uma série de direitos podem vir a serem violados.

Portanto, quando o Estado permite que a dignidade da pessoa humana seja afetada, abre espaço para que seus demais direitos sejam violados. Em contrapartida, quando há violação de direitos de determinado segmento social, apresentam-se como protagonistas os movimentos sociais ${ }^{4}$ para lutar perante ao Estado, junto à sociedade civil em defesa de tais diretos, deste nodo, este trabalho faz referência e tem como suporte o ideário do

4 Entendemos como Movimento Social um grupo de pessoas de determinado segmento que luta e reivindica por diferentes bandeiras de lutas, a fim de garantir a implementação de políticas públicas por parte do Estado, com o intuito de promover os direitos humanos e combater a violação dos mesmos. 


\section{dAEPEI}

movimento social $\mathrm{LBGT}^{5}$.

\section{Breve histórico do Movimento Social LGBT}

O movimento social LGBT tem como marco histórico o dia 28 de junho de 1969, quando um grupo de pessoas LBGT iniciou um tumulto liderado por Sylvia Rivera, $\operatorname{trans}^{6}$ e bissexual, comandante da maior parte das manifestações incluindo os "riots" ${ }^{7}$ que abalaram a cidade de Nova York, perdurando três dias. A partir deste dia, a data passaria a ser reconhecida internacionalmente como a "Revolta de Stonewall". Stonewall era a denominação de um bar, localizado em Nova York (EUA), frequentado pelo público LGBT, que na época sofria com a constante perseguição policial sem justificativas.

Desde então, todo ano, a data é celebrada como o dia internacional do orgulho LGBT, quando pessoas desse grupo expressam de forma orgulhosa sua orientação sexual e identidade de gênero, dando surgimento ao que hoje são conhecidas como "Paradas do Orgulho LGBT", que no Brasil, tornaram-se momentos de expressão e visibilidade a partir de $1995^{8}$. No entanto, o movimento social LGBT foi muito mais além do que ter uma data histórica de luta. As entidades deste movimento social espalhadas por todo mundo lutam constantemente contra violação dos direitos humanos de pessoas LGBT, reivindicando direitos igualitários, sem discriminação, relativos à orientação sexual e identidade de gênero. Esta militância tem alcançado relevante espaço e grandes conquistas no que tange aos direitos da população LGBT.

Outro fator importante para a organização destes movimentos está relacionado ao crescimento do número de pessoas infectadas com o vírus HIV na década de 90, epidemia que na época chegou a ser chamada de "câncer gay", denominação decorrente de preconceito em relação a pessoas LGBT. Desde então, o movimento social LGBT passou também a se organizar em prol da prevenção de DST/AIDS, assim como combater esse

5 Sigla que designa Lésbicas, Gays, Bissexuais, Travestis e Transexuais.

6 Pessoa que não são identifica com o gênero que lhe foi determinado no nascimento

7 É uma forma de desordem civil comumente caracterizada por um grupo batendo em uma perturbação da ordem pública violenta contra autoridade, propriedade ou pessoas.

8 Nossa primeira "Parada" aconteceu em 2007 no Estado de São Paulo, reunindo cerca de 2.000 pessoas com o tema "somos muitos, estamos em todas as profissões". 
estigma que essa população carregou durante um grande período.

No Brasil, temos inúmeras entidades do movimento social LGBT espalhadas por todo país. À frente do movimento em defesa dos direitos básicos de pessoas trans, por exemplo, temos como referência nacional a ANTRA (Articulação Nacional de Travestis e Transexuais) que quando fundada tinha como significado de sua sigla: articulação nacional de transgêneros que, por questões políticas, foi alterada para a nomenclatura atual.

No estado do Pará, o Movimento Social só começou a se organizar a partir do ano de 2008, quando foi realizada a primeira Conferência LGBT, que aconteceu na sede do Sindicato dos Bancários. Surgiu então, o GHP (Grupo Homossexual do Pará), primeiro grupo LGBT do estado. A partir daquele ano, tendo em vista a necessidade de organização dos demais seguimentos LGBT do interior do estado, começaram a surgir outros grupos organizados à ótica dos movimentos sociais. Alguns destes movimentos filiaram-se à ABGLT $^{9}$ (Associação Brasileira de Lésbicas, Gay, Bissexuais, Travestis e Transexuais), tendo em vista a necessidade de uma maior articulação com os demais grupos do país. Desde então, o Movimento Social LGBT do estado do Pará começou a desenvolver um excelente trabalho no que se refere ao movimento de luta e reivindicação das principais bandeiras de militância de sujeitos LGBT do estado.

O trabalho desenvolvido segue na linha de prevenção das DSTs/AIDS, combate às diversas formas de discriminação em razão das orientações sexuais e identidades de gênero, palestras e eventos com amplo debate acerca da diversidade sexual em diversas instituições, inclusive nas escolas e universidades do Estado do Pará. Neste sentido, é importante ressaltar que o Movimento Social também pode exercer um papel importante relativo à promoção do direito à educação, reivindicando dos governantes a implementação de

\footnotetext{
9 A ABGLT foi criada em 31 de janeiro de 1995, com 31 grupos fundadores, sendo hoje uma rede nacional de 308 organizações afiliadas. É a maior rede LGBT na América Latina. Atualmente as linhas prioritárias de sua atuação incluem: o monitoramento da implementação das decisões da I Conferência Nacional LGBT; o monitoramento do Programa Brasil Sem Homofobia; o combate à homofobia nas escolas; o combate à Aids e outras doenças sexualmente transmissíveis; o reconhecimento de Orientação Sexual e Identidade de Gênero como Direitos Humanos no âmbito do Mercosul; advocacy no Legislativo, no Executivo e no Judiciário; a capacitação de lideranças lésbicas em direitos humanos e advocacy; a promoção de oportunidades de trabalho e previdência para travestis; a capacitação em projetos culturais LGBT.
} 


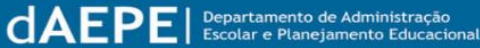

políticas públicas com que garantam aos LGBT o exercício deste direito, inclusive de pessoas trans.

\section{Sexo, gênero e identidade de gênero}

Para iniciar o debate acerca das estudantes travestis e transexuais, faz-se necessário discutir importantes conceitos que nos dão condições de ter uma percepção dessas existências na instituição escolar. Em relação ao sexo, partiremos do conceito desenvolvido por Jaqueline Gomes de Jesus, que o define a partir de uma:

Classificação biológica das pessoas como machos ou fêmeas, baseada em características orgânicas como cromossomos, níveis hormonais, órgãos reprodutivos e genitais. Ao contrário da crença popular, reiterada em diferentes discursos, a categoria sexo não se configura como uma dualidade simples e fixa entre indivíduos deste e daquele sexo (binarismo ou dimorfismo sexual), mas, isso sim, como um contínuo complexo de características sexuais. (JESUS, 2012, p. 24).

Neste sentindo, a definição de sexo não pode ser entendida apenas pela perspectiva de uma classificação biológica e natural, visto que a ideia de sexo também é constituída por práticas discursivas que reiteram modos de ser e de existir, produzindo os corpos no sentido de atender a uma matriz heterossexual, conforme defende Judith Butler (2000). Para a autora:

A categoria do "sexo" é, desde o início, normativa: ela é aquilo que Foucault chamou de "ideal regulatório". Nesse sentido, pois, o "sexo", não apenas funciona como uma norma, mas é parte de uma prática regulatória que produz os corpos que governa, isto é, toda força regulatória manifesta-se como uma espécie de poder produtivo, o poder de produzir - demarcar, fazer, circular, diferenciar - os corpos que ela controla. (Ibidem, p. 151).

Quanto à definição de gênero, a expressão corresponde à "classificação pessoal e social das pessoas como homens ou mulheres, orienta papéis e expressões de gênero. Independe do sexo" (JESUS, 2012, p. 24). Porém, vale ressaltar que a construção de gênero se constitui a partir de uma perspectiva cultural, já estabelecida pelo sexo de designação médica do sujeito, ou seja, uma pessoa ao nascer, já tem em torno de si o que 


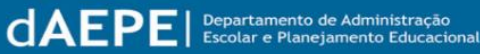

podemos chamar de um "mundo azul" ou um "mundo cor-de-rosa", criado culturalmente de acordo com designação, corroborando os determinantes sócio-históricos que reforçam o binarismo masculino/feminino ou homem/mulher no que diz respeito ao sexo/gênero do sujeito.

No que se refere à identidade de gênero, define-se como sendo o:

Gênero com o qual uma pessoa se identifica que pode ou não concordar com o gênero que lhe foi atribuído quando de seu nascimento. Diferente da sexualidade da pessoa. Identidade de gênero e orientação sexual são dimensões diferentes e que não se confundem. Pessoas transexuais podem ser heterossexuais, lésbicas, gays ou bissexuais, tanto quanto as pessoas cisgêneros. (JESUS, 2012, p. 24).

No entanto, entre as identidades de gênero existentes no campo da sexualidade humana, existe a Identidade Trans. A transgeneridade consiste na não conformidade da identidade de gênero com a designação médica de nascimento, caso da pessoa travesti que, conforme a definição de Jesus, trata-se de:

Pessoa que vivencia papéis de gênero feminino, mas não se reconhece como homem ou mulher, entendendo-se como integrante de um terceiro gênero ou de um não-gênero. Referir-se a ela sempre no feminino, o artigo "a" é a forma respeitosa de tratamento. (JESUS, 2012, p. 28).

Já pessoas transexuais, por sua vez, reivindicam o reconhecimento social e legal como mulher ou como homem. Em alguns casos, também se denominam transhomens ou transmulheres (JESUS, 2012). Porém, e infelizmente, ainda vivemos em uma sociedade cis-heteronormativa, que se constitui a partir da "crença na heterossexualidade como característica do ser humano 'normal'. E, "desse modo, qualquer pessoa que saia desse padrão é considerada 'fora da norma', o que justificaria sua marginalização” (JESUS, 2012, p. 29), decorrente de normas e condutas reproduzidas por diversas instituições, entre elas a escola.

É, portanto, a partir do sistema corpo-sexo-gênero que pessoas travestis e transexuais são marginalizadas em nossa sociedade. Para pensar este sistema, as teorizações de Judith Butler são potentes indagações para repensar o corpo pois, conforme a autora, o corpo se materializa de forma sexuada e generificada, apontando que o gênero antecede o corpo e o sexo. Para Butler: 
[...] o 'sexo' é um constructo ideal que forçosamente materializado através do tempo. Ele não é um simples fato ou a condição estática de um corpo, mas o processo pelo qual as normas regulatórias materializam o 'sexo' e produzem essa materialização através de uma reiteração forçada destas normas. $\mathrm{O}$ fato de que essa reiteração seja necessária é um sinal de que a materialização não é nunca totalmente completa, que os corpos não se conformam, as normas pelas quais sua materialização é imposta. (BUTLER, 2000, p. 152).

Neste sentido, é imprescindível pensarmos o sistema corpo-sexo-gênero sem atrelá-los a formulação a partir dos estudos feministas, argumentando, por exemplo, que gênero "[...] pretende se referir ao modo como as categorias sexuais são compreendidas e representadas, ou, então, como 'são trazidas para a prática social e tornadas parte do processo histórico"” (LOURO, 1997, p. 22). Entendendo que a sociedade se organiza de forma generificada, ao fazer emergir o debate acerca do gênero como um a categoria analítica, pretende-se:

[...] recolocar o debate no campo do social, pois é nele que se constroem e se reproduzem as relações (desiguais) entre os sujeitos. As justificadas para as desigualdades precisariam ser buscadas não nas diferenças biológicas (se é que mesmo essas podem ser compreendidas fora de sua constituição social), mas sim nos arranjos sociais, na história, nas condições de acesso aos recursos da sociedade, nas formas de representação. (LOURO, 1997, p. 22)

Mas (re)pensar a produção de corpos trans, desde o nascimento até os conflitos vividos na infância e ao longo da vida a partir das divergências advindas das fissuras e transgressões das normas, é necessário trazer para o debate a dimensão de como as relações de poder interpelam as questões relacionadas ao sexo. Para Foucault:

O poder seria, essencialmente, aquilo que dita a lei, no que diz respeito ao sexo. $\mathrm{O}$ que significa, em primeiro lugar, que o sexo fica reduzido, por ele a regime binário: lícito e ilícito, permitido e proibido. Em seguida, que o poder prescreve ao sexo uma 'ordem' que funciona, ao mesmo tempo, como forma de inteligibilidade: o sexo se decifra a partir de sua relação com a lei. E, enfim, que o poder age pronunciando a regra: o domínio do poder sobre o sexo seria efetuado através da linguagem, ou melhor, por um ato de discurso que criaria, pelo próprio fato de se enunciar, um estado de direito. Ele fala e faz a regra. A forma pura do poder se encontraria na função do legislador; e seu modo de ação com respeito ao sexo seria jurídico-discursivo. (FOUCAULT, 2014, p. 91).

Neste sentido, a partir de um processo linguístico-discursivo, Butler (2000) 


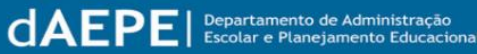

defende que tanto o gênero quanto o sexo são constituídos, a partir de uma performatividade, constituído por processos discursivos e linguísticos, pensamos que aspectos discursivos também têm constituído corpos e práticas atravessados pela categoria da diferença de gênero. Portanto, neste sentido o conceito de performatividade que foi proposto por Justin Austin (1998), alerta sobre as dimensões de operação de uma das categorias de proposições da linguagem, a proposição performativa, a qual faz com que algo se efetive e se realize, a partir dos enunciados (SILVA, 2014). Conforme Silva:

\begin{abstract}
Em seu sentido estrito, só podem ser consideradas performativas aquelas proposições cuja enunciação é absolutamente necessária para a consecução do resultado que anunciam. Entretanto, muitas sentenças descritivas acabam funcionando como performativas. Assim, por exemplo, uma sentença como "João é pouco inteligente", embora pareça ser simplesmente descritiva, pode funcionar - em um sentido mais amplo - como performativa, na medida em que sua repetida enunciação pode acabar produzindo o 'fato' que supostamente deveria descrevê-lo. (2014, p. 93).
\end{abstract}

\section{A inserção de travestis e transexuais no ambiente escolar}

Estudos de Reis (2012) e Santos (2010) comprovam que pessoas LGBT no decorrer de suas vidas são vítimas de muito preconceito e discriminação, principalmente no ambiente escolar. No entanto, um homem gay ou uma mulher lésbica podem, muitas vezes, passar despercebidos, mas sujeitos travestis e transexuais, por sua vez, podem por um período de sua vida, negar ou esconder sua identidade de gênero, em determinado momento, tal sujeito ao aceitar sua própria identidade, deflagra um processo transexualizador. No caso das transexuais o processo se constitui em:

um conjunto de alterações corporais e sociais que possibilitam a passagem do gênero atribuído (biologicamente) para o identificado (ao qual o sujeito reconhece seu pertencimento), e pressupõe um protocolo a que todas as pessoas transexuais que almejam ser reconhecidas como de outro gênero precisam se submeter" (BENTO, 2006 apud SANTOS, 2009, p. 4426).

Já as travestis passarão a inserir em seus corpos e adotar comportamentos do universo feminino, o que não quer dizer que almejem ser reconhecidas como mulheres, porém, seus hábitos e seus comportamentos não corresponderão ao papel social atribuído a 


\section{dAEPEI}

sujeitos com designação como masculino.

Cézar (2009) afirma que com a ampliação da democratização da educação básica no Brasil, fomentado pelo princípio da inclusão social e pelas demandas do movimento social LGBT, as investigações sobre a temática da exclusão de pessoas trans das escolas brasileiras têm alcançado significativos espaços. Pessoas travestis e transexuais, através das modificações em seus corpos, confrontam-se com o dispositivo da sexualidade descrito por Foucault (2014). Para o autor contra o dispositivo da sexualidade, o ponto de apoio de contra-ataque não deve ser o sexo-desejo, mas os corpos e os desejos.

De acordo com Cézar (2009) em seu livro História da sexualidade: a vontade do saber (2014), Michael Foucault colocou em xeque a ideia de sexualidade que atravessou o século XX como o elemento organizador das subjetividades. Neste sentido, cabe problematizar os corpos dos sujeitos trans dentro da instituição escolar, a partir de uma análise na ótica do dispositivo da sexualidade descrita por Foucault, pautando os desdobramentos de como tais sujeitos possam criar mecanismos de subversão. Pois de acordo com Foucault (2014, p. 91), “com respeito ao sexo, o poder jamais estabelece relação que não seja de modo negativo: rejeição, exclusão, recusa, barragem ou, ainda, ocultação e mascaramento".

Em decorrência disso, sujeitos trans ao inserirem-se no espaço escolar, se deparam com a dura realidade de um contexto de transfobia, que se constitui no "preconceito e/ou discriminação em função da identidade de gênero de pessoas transexuais ou travestis" (JESUS, 2012, p. 29). Em várias mídias, têm-se observado falas de transexuais que denunciam um sutil e perverso maquinário dentro das escolas públicas e privadas que, em pleno funcionamento, expulsam e mantêm esses sujeitos fora delas (SANTOS, 2009). Outra consequência mais grave ainda, em decorrência da transfobia, é a não aceitação destes sujeitos no ambiente escolar, como observamos no relato de Sarita:

[...] depois a gente viajou pra Santarém, fui trabalhar pra lá, a moça foi me matricular, mas a diretora não me aceitou. Primeiro ela viu meu nome, aí ela pediu pra me levar lá, só que quando ela me viu, ela disse que não, que não tinha mais vaga, ela viu que eu era uma travesti e foi preconceituosa, aí não fizemos nada, fiquei calada, isso com 19 anos, fiquei dois anos e meio sem estudar. 
Em meio a este contexto transfóbico que a escola tem revelado, travestis e transexuais, cada vez mais, têm evadido desse ambiente educacional, sem conseguirem concluir seus processos formais de escolarização. Segundo a entidade ANTRA (Articulação Nacional dos Travestis, Transexuais e Transgêneros), há uma estimativa indicando que $90 \%$ das travestis e transexuais estão na prostituição, enquanto um percentual de apenas 3\% a 5\% estuda. Para Keila Simpson, presidente da ANTRA, em entrevista a Gazeta do Povo (2009) “a evasão escolar em razão do preconceito é uma realidade. Eles não estudam porque não querem [sic], mas porque as escolas se fecharam" (PARO, 2009) .

Por outro lado, ao analisar o processo de escolarização de pessoas trans, é possível identificar algumas dificuldades enfrentadas por estes sujeitos na escola por estarem identificados(as) como diferentes (BRAGA, 2012). Iremos aqui pautar três ${ }^{10}$ dos principais aspectos, que são motivos de reivindicação do movimento LGBT, ou que muitas vezes, são silenciados e invisibilizados por serem confrontados de forma solitária por tais sujeitos, ocasionando sua evasão do sistema escolar.

\section{O nome social e o reconhecimento identitário}

A partir da construção da identidade de pessoas trans, de acordo com o gênero pelo qual o sujeito se reconhece, há a escolha do nome social que segundo Santos (2010, p. $56)$ :

O significado desse nome é construído juntamente com a identidade de gênero fabricada pelas transexuais e travestis como uma espécie de legenda, isto é, uma identidade diante do mundo e, sobretudo materializa a nova identidade produzida pela construção do corpo.

Conforme os relatos de travestis e transexuais: ${ }^{11}$

O nome civil é uma das inconformidades da real identidade de gênero de tais sujeitos. Uma menina/mulher transexual que nasce num corpo biológico masculino, com genitália masculina, possui um nome masculino que lhe foi

10 São eles; o nome social, o uso do banheiro e a interação com a comunidade que compõe a escola. 11 Veja-se o trabalho de SANTOS $(2009 ; 2010)$ 
atribuído na ocasião do registro do seu nascimento. No entanto, ela não se reconhece nesse corpo e inicia uma construção do seu corpo e da sua identidade de gênero, com elementos do universo feminino. Quando ela procura se matricular em uma escola pública, apresenta-se, por exemplo, com roupas, acessórios e elementos do gênero feminino em desacordo com o sexo biológico e com seu nome civil. No entanto, a escola utiliza - aprisionada à norma - o nome civil masculino que ao ser pronunciado por professoras, professores e colegas provoca constrangimento e expõe a transexual a situação vexatória e humilhante permanentemente. (BENTO, 2008 apud SANTOS, 2009, p. 4429).

No contexto voltado para a instituição escolar, podemos observar claramente a negação da identidade de gênero de pessoas trans por parte da escola e de todos os seus atores, decorrente da falta de uma educação que atenda qualquer identidade de gênero. Em função do desrespeito à identidade destas alunas, elas sofrem um constrangimento diário dentro da escola que muitas vezes, ultrapassam os muros das instituições escolares como podemos observar no relato da interlocutora desta pesquisa Sarita Chay:

\footnotetext{
$\mathrm{Na}$ escola os meninos riam do meu nome, diziam 'esse nome é famoso sabia' tinha alguns meninos que chamavam de Max na rua, aí eu dizia: - vocês me chamam de Max no colégio como a professora falou e na rua me chamam pelo nome de Sarita, pois eu não gosto deste nome, acho feio, aí eles falavam: - 'não, teu nome é bonito, é um nome famoso'. Aí começavam a me apelidar, e eu não gostava.
}

Diante da necessidade do reconhecimento de identidade através do nome social, o movimento social LGBT tem se mobilizado para que esse direito possa ser reconhecido e garantido. No Pará, no ano de 2008 a Secretaria de Estado Educação (SEDUC) expediu a Portaria $n^{\circ} 16 / 08$, que estabelece em seu artigo $1^{\circ}$ que "a partir de 02 de janeiro de 2009 , todas as Unidades Escolares da Rede Pública Estadual do Pará passarão a registrar, no ato da matrícula dos alunos, o pré-nome social de Travestis e Transexuais” (PARÁ, 2008, p. $81)$.

Em que pese o pioneirismo e a legitimidade da iniciativa sabe-se que não basta apenas uma decisão do Poder Executivo para que a situação de discriminação seja revertida. A grande mudança que a sociedade LGBT necessita deve ser decorrente de uma mudança cultural, que advenha de uma nova educação, pois segundo relatos de travestis e 


\section{dAEPE|}

transexuais ${ }^{12}$ ainda há grande resistência por parte da instituição escolar em relação ao atendimento pelo nome social, reforçando uma circunstância agravante na permanência de pessoas trans nesse ambiente educacional.

\section{Uso do banheiro e a (des)construção das normas de gênero}

No cotidiano escolar das alunas trans, outra grande dificuldade enfrentada, se dá no uso do banheiro. O que para os alunos cisgêneros ${ }^{13}$ é algo simples, por estarem enquadrados na normativa de gênero, para as alunas trans torna-se um embate no dia-a-dia dentro da escola. O binarismo homem-mulher, definido por determinantes biológicos existente na sociedade como um todo e no contexto escolar em particular, bem como em outras instituições sociais, silenciosamente é afirmado de diversas formas. Se tratando de um binarismo, obviamente, será excluso todo aquele que não se enquadrar nas normativas já existentes, sofrendo a tentativa de (des)construção da sua identidade de gênero, o que significa uma afronta ao seu direito como ser humano.

Para citar exemplos mais atuais relacionados à reprodução do binarismo no cotidiano das instituições escolares, tem-se a divisão por sexo nas aulas de Educação Física - e os esportes atribuídos a meninos ou meninas; as filas de meninos e de meninas em determinadas situações; as divisões sexistas de vestuário - meninos não podem usar brincos nem cabelo comprido; as formas dos professores tratarem homens ou mulheres; com rispidez ou com delicadeza; a tolerância da violência verbal e até mesmo física entre meninos são alguns dos exemplos da forma sob a qual a escola silenciosamente controla a sexualidade e os corpos diariamente (BERTOLINI, 2008).

Nos últimos anos, o movimento social LGBT tem recebido diversas denúncias em relação a constantes constrangimentos de alunas trans em relação ao uso do banheiro, pois reivindicam junto à coordenação das escolas o uso do banheiro feminino. Por outro lado, essas reivindicações não têm sido atendidas, quando há insistência das alunas trans, há

12 Ver trabalho de Santos (2009)

13 Conceito "guarda-chuva" que abrange as pessoas que se identificam com o gênero que thes foi determinado quando de seu nascimento (JESUS, 2012, p. 25). 


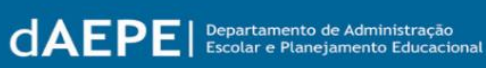

resistência por parte das demais alunas da escola.

Na maioria dos casos, a orientação da escola é de que as alunas trans utilizem o banheiro masculino, medida contra quais as alunas travestis e transexuais se opõem, tendo em vista que, conforme seus relatos, ao utilizarem o banheiro masculino são vítimas de constantes constrangimentos e expostos a todo tipo de violência simbólica e física, inclusive correndo risco de sofrerem estrupo.

Recentemente foi veiculado na internet, o caso de uma aluna trans no município de Campo Grande (MS) que reivindicava o uso do banheiro feminino. Uma equipe de telejornal se dirigiu à escola para realizar uma reportagem sobre o assunto e, ao entrevistar outras alunas, fez-se notável o preconceito com a aluna transexual, por meio de discursos de desconstrução de seu gênero. Até mesmo a "solução" momentânea encontrada pela coordenação da escola - aconselhando que a aluna utilizasse o banheiro masculino dos professores - revelou-se preconceituosa e discriminatória (FRANCO, 2013).

Há registros também, em outros casos semelhantes, nos quais se cogitou a criação de um banheiro exclusivo para alunas travestis e transexuais, ato que fere igualmente aos ideais do movimento social LGBT, por criar um movimento de exclusão e segregação desses sujeitos, na medida em que são pessoas que se identificam ao sexo feminino, portanto, sendo justa a utilização do espaço designado para tal sexo.

\section{A interação cotidiana com o outro na escola}

Conforme abordado anteriormente, sabe-se que a instituição escolar controla de forma silenciosa a sexualidade dos sujeitos e seus corpos, contribuindo de forma negativa para a divisão de gênero. A título de exemplo, podemos fazer referência às brincadeiras infantis que, por sua vez, são divididas em ações de meninos e de meninas, seja nas atividades de educação física ou no intervalo, entre tantas outras formas de separação de alunos por gênero.

Todavia, onde se enquadra o sujeito com identidade de gênero que transcende as definições convencionais de sexualidade? Depara-se, então, com mais um motivo de 


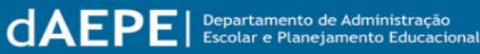

segregação e marginalização dentro das instituições escolares. A separação binária de gênero que a escola estabelece acaba deixando as alunas trans sem espaço em determinadas atividades, tendo em vista que as demais alunas não as aceitam por não as reconhecerem como pessoas pertencentes ao sexo feminino e, de certa forma, se as aceitassem outros problemas seriam previstos, como, por exemplo, os (as) professores (as) insistirem que elas deveriam brincar com meninos, aprisionados a norma, em decorrência de terem nascido biologicamente pertencentes ao sexo masculino.

Com os alunos do sexo masculino também, geralmente há um relacionamento áspero e delicado, tendo em vista que na maioria das vezes, as alunas trans não se identificam com elementos do universo masculino e também enfrentam forte preconceito e discriminação, que se materializam em xingamentos, apelidos pejorativos e, na pior das hipóteses, em agressões físicas, conforme o relato a seguir:

\begin{abstract}
Tinha uma garota que me criticava, uma vez eu furei ela com um lápis que a ponta quebrou e ficou dentro do braço dela, porque ela veio me xingar, disse que eu era um veado. E, um outro que batia na minha bunda e me chamava de bunda de moça, me chamava de moça e eu chorava de raiva, eu ainda não me aceitava direito, por que não queria que meus pais soubessem [...] e isso era todo dia, não tinha paz, eu fugia da escola. Aí, minha mãe me perguntava por que eu não estava na escola, e eu dizia pra ela, que aquele moleque me bateu e me xingou de moça, me chamava de mulherzinha, que minha bunda era igual de moça. Aí eu chorava, essa moleca também começava a me xingar, aí eu furei com lápis e a ponta do lápis ficou dentro do braço, daí então os professores me mandavam ir embora, aí eu não quis mais ir pra escola. (SARITA CHAY)
\end{abstract}

\section{Considerações Finais}

A escola, de fato, ainda não é lugar para as pessoas trans, pois, como vimos, a interação das alunas travestis e transexuais com seus professores e colegas, na maior parte das vezes, são caracterizados em um contexto de transfobia, que é enfrentado diariamente e sem apoio institucional, pois as instituições, de diferentes formas, desconhecem as identidades trans.

No que diz respeito à postura das instituições diante da transexualidade, Braga (2012) destaca que: 
Quando a questão refere-se à Transexualidade as dificuldades se acentuam, principalmente porque se relacionam a pessoas cuja posição está fixada no imaginário social como sujeitos que transgridem e, portanto, ameaçam a ordem normativa, as convenções sociais de corpo, do gênero e da sexualidade. Suas experiências nos mostram o que é crescer como pessoa sem importância, obrigada a sustentar a perigosa visibilidade dos seus corpos e de seus desejos ou a ocultar sua incômoda diferença - invisibilizando-se nas relações sociais cotidianas. (BRAGA, 2012, p. 18).

Essa reflexão corrobora a importância da instituição escolar desenvolver uma política de relações institucionais que trabalhe cotidianamente um programa de educação de diversidade sexual e de gênero, para que seja garantido o direito à educação de todo e qualquer cidadão independente de sua identidade. É patente a necessidade de todos aqueles que compõem o ambiente escolar debaterem a respeito das identidades dissidentes -que sempre existiram, mas que por muito tempo estiveram completamente invisibilizadas.

Para isso, é necessário ser desenvolvido um trabalho sobre a diversidade sexual nas escolas, pressupondo:

Um conhecimento das disposições de professoras e professores, que por sua vez precisam adentrar em uma nova lógica do (des)conhecer, e não poderão jamais ser as perguntas formuladas aos especialistas - é normal menino virar menina? Por que eles são assim? Qual a causa disso? Questionar sobre a normalidade é pertencer ao mundo definido e mapeado pelos processos disciplinadores e normalizadores. (SANTOS, 2009, p. 4431).

Apesar do contexto adverso, uma pessoa ao descobrir-se e assumir-se trans não se torna menos digna. Mesmo assumindo uma identidade divergente, a estabelecida pelas normas sociais e culturais de gênero, deve ter seu direito à educação garantida, ocupando um espaço que é sua prerrogativa. A luta pela garantia do direito à educação de toda e qualquer pessoa é urgente, para que todas e todos possam exercer sua cidadania plena e que não ouçamos discursos carregados de tristeza, como da nossa entrevistada:

Eu não sinto vontade de voltar estudar, as pessoas me perguntam por que eu não volto estudar, faço um curso. Mas eu desisti e ponto final. Quando eu estudava eu gostava muito mesmo, eu tirava só notas boas em matemática, ciências e história, eu sempre gostei de estudar, eu sinto vontade, mas eu prefiro não, fico quieto na minha, pois eu sei se eu voltar terei raiva de novo... Mas por mim eu voltaria, mas prefiro trabalhar do que estudar e ponto final. (SARITA CHAY) 


\section{REVISTA DE ADMINISTRAÇÃO EDUCACIONAL}

\section{ISSN -2359-1382}

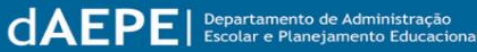

Infelizmente, essas e outras questões não estão sendo respondidas pelas instituições e o único movimento que se tem visto é o de exclusão desses sujeitos para fora do ambiente escolar, contribuindo para a marginalização de travestis e transexuais, que na maioria das vezes veem como saída para sua sobrevivência às ruas, em meio à prostituição. Superar essa injustiça é nosso grande desafio. É o grande desafio da escola brasileira.

\section{Referências}

BORTOLINI, Alexandre. Diversidade Sexual na Escola. Rio de Janeiro: Editora PUFRJ, 2008.

BUTLER, Judith. Corpos que pesam: sobre os limites discursivo do "sexo". LOURO, Guacira Lopes (org.). Belo Horizonte: Autentica Editora, 2000.

BRAGA, Denise da Silva. Experiência transexual: estigma, estereótipo e desqualificação social nos intramuros da escola. Periferia: Revista de Programa de Pós-Graduação em Educação, Cultura e Comunicação, Rio de Janeiro, v. 4, n. 1, p. 1-20, 2012.

CÉSAR, Maria Rita de Assis. Um nome próprio: transexuais e travestis nas escolas brasileiras. FILHA, Constantina Xavier (org.). Campo Grande: Editora UFMS, 2009.

FOUCAULT, Michael. História da sexualidade: A vontade de saber. São Paulo. Editora: Paz e Terra, 2014.

FRANCO, William. Estudante travesti vive dilema por não poder usar banheiro feminino de escola. Campo Grande: MS Record, 2013.

PARO, Denise. Entidades querem que a escola use nome social. Gazeta do povo. Curitiba, 07/01/2009

LEITE, Carlos Henrique Bezerra. Direitos Humanos. Rio de Janeiro: Lumen Juris, 2011.

LOURO, Guacira Lopes. Gênero, Sexualidade e Educação. Uma perspectiva pósestruturalista. Rio de Janeiro: Vozes, 1997.

JESUS, Jaqueline Gomes de. Orientações sobre identidade de gênero: conceitos e termos. Brasília, 2012.

PARÁ. Portaria n⿳0 16, de 10 de abril de 2008. Belém: Diário Oficial do Estado do Pará, 2015.

PARO, Denise. Entidades querem que escola use nome social. Curitiba: Gazeta, 2009. 


\section{REVISTA DE ADMINISTRAÇÃO EDUCACIONAL}

\section{ISSN -2359-1382}

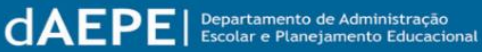

REIS, Antônio Luiz Martins dos. O silêncio está gritando: A homofobia no ambiente escolar, um estudo qualitativo no ensino fundamental de escolas públicas em Curitiba. Tese de Doutorado, Universidade de la Empresa, 2012.

SANTOS, Dayana Brunetto Carlin dos. Cartografia da transexualidade: a experiência escolar e outros tramas. Dissertação de Mestrado. PPGE, Universidade Federal do Paraná, 2010.

SANTOS, Dayana Brunetto Carlin dos. Nome Social de travestis e transexuais na escola básica: Política Pública Afirmativa ou capricho? In: IX Congresso Nacional de Educação, Curitiba, 2009.

SILVA, Tomaz Tadeu. Identidade e Diferença: A perspectiva dos Estudos Culturais. Editora Vozes, 2012. 